\title{
CONSIDERAÇÕES A RESPEITO DA POSIÇÃO DE PROIBIÇÕES DE DISCRIMINAÇÃO NO SISTEMA DO DIREITO PRIVADO ${ }^{1}$
}

\author{
REMARKS ON THE DISCRIMINATION PROHIBITIONS' ROLE \\ IN THE PRIVATE LAW SYSTEM
}

\author{
CLAUS-WILHELM CANARIS ${ }^{2}$
}

\begin{abstract}
RESUMO: A existência de proibições de discriminação que geram efeitos na esfera das relações entre atores privados constitui evidência de que o direito privado é regido não apenas pela justiça comutativa, mas também pela justiça distributiva. Tais normas de proibição assumem caráter de normas cogentes de Direito Privado e não de Direito Público. As proibições de discriminação têm fundamentos diferentes, como a proteção da dignidade humana ou finalidades sociopolíticas. É possível classificá-las conforme suas funções teleológicas. As proibições fundadas na proteção da dignidade vinculam os atores privados diretamente, ao passo que as demais têm eficácia indireta - são estabelecidas e configuradas pelo legislador.
\end{abstract}

PALAVRAS-CHAVE: Proibições de Discriminação; Direito Privado; Dignidade Humana; Direitos Fundamentais.

\begin{abstract}
The existence of prohibitions of discrimination that generate effects in the relationship sphere of private actors serves as evidence that Private Law é guided by distributive as well as corrective justice. Such rules of prohibition take on the role of enforceable legal norms of Private Law, not of Public Law. Discrimination bans have diverse grounds, such as the protection of human dignity and socio-political objectives. It is therefore possible to classify them by teleological criteria. Discrimination prohibitions based on the protection of human dignity bind private actors directly, while the rest of them have merely indirect efficacy - they are established and designed by the legislator.

KEYWORDS: Discrimination Prohibitions; Private Law; Human Dignity; Fundamental Rights.
\end{abstract}

\footnotetext{
Artigo recebido em 28.01.2013. Artigo aceito para publicação em 10.03.2013 mediante convite.

1 O presente texto corresponde à versão em língua portuguesa da conferência proferida pelo autor na Pontifícia Universidade Católica do Rio Grande do Sul, em 12.09.2012, por ocasião de Congresso Internacional sobre os 10 Anos do Código Civil Brasileiro. A tradução é de Ingo Wolfgang Sarlet, Professor Titular e Coordenador do PPGD da PUCRS.

${ }^{2}$ Professor Catedrático Emérito de Direito Privado e Filosofia do Direito da Universidade de Munique, Alemanha. Doutor Honoris Causa pelas Universidades de Lisboa, Autônoma de Madrid, Atenas, Verona e Pontifícia Universidade Católica do Rio Grande do Sul.
} 
Alta Faculdade, estimados Senhoras e Senhores.

Como agradecimento pela excepcional honra que foi concedida ${ }^{3}$, gostaria de dedicar esta conferência. O seu objeto foi escolhido de tal sorte a abordar problemas que considero possam ser também interessantes do ponto de vista brasileiro e que ainda assim guardem relação com minha pessoal trajetória científica. Além disso, a ideia foi enfrentar um tema em relação ao qual tenho algo de novo a dizer, de tal sorte que não estou lhes apresentando uma mera compilação de pensamentos por mim já externados da mesma forma ou de modo similar. Por tal razão vou discorrer sobre proibições de discriminação no Direito Privado. Com tal tópico acabei me ocupando apenas de modo marginal e jamais de forma intensiva, muito embora a temática guarde, em determinados sentidos, estreita relação com conteúdos que tem ocupado um lugar central no âmbito de minha atividade científica.

Irei enunciar quatro teses.

Primeiro: a existência de proibições de discriminação que geram efeitos na esfera das relações entre atores privados constitui evidência de que, em sentido contrário ao que ainda vem sendo sustentado por amplos setores, o sistema do Direito Privado não é regido exclusivamente pela justiça comutativa, mas está colocado, em diversos aspectos, ao serviço da justiça distributiva.

Segundo: proibições de discriminação que dizem respeito às relações entre particulares assumem, a despeito de seu caráter cogente, a condição de normas jurídicas de Direito Privado. Isso vale independentemente de qual seja o critério adotado para estabelecer a distinção entre o Direito Público e o Direito Privado.

Terceiro: existem diversos motivos para o estabelecimento de proibições de discriminação. O mais importante reside na ameaça e mesmo violação da dignidade humana. Paradigmáticas são, nesse sentido, discriminações em virtude da raça e da religião. Outros motivos dizem respeito a - em parte contingenciais - determinações de finalidades de natureza sociopolítica por parte do legislador "ordinário". Aqui se revela referencial o postulado da igualdade de condições entre homens e mulheres no âmbito do mercado de trabalho e exercício profissional. Resulta evidente que as fronteiras entre tais tipologias básicas são fluídas, mas elas podem, na sua essência, ser claramente diferenciadas e separadas por razões teleológicas no âmbito da jurisprudência.

Quarto: as proibições de discriminação fundadas na dignidade humana e na sua proteção vinculam diretamente (no âmbito de uma eficácia em relação a terceiros ou eficácia privada) os atores privados. No mais, é reservada ao

\footnotetext{
${ }^{3}$ A referência é feita à outorga do título de Doutor Honoris Causa pela PUCRS no dia 12.09.2012 pela manhã, acolhendo proposição feita pelo Programa de Pós-Graduação em Direito (coordenado pelo Prof. Dr. Ingo Wolfgang Sarlet) e da Direção da Faculdade de Direito (exercida pelo Prof. Dr. Fabrício Pozzebon) da mesma Universidade.
} 
legislador "ordinário" a possibilidade de estabelecer proibições de discriminação e formular os respectivos suportes fáticos e efeitos jurídicos.

II.

Há praticamente dois mil e quinhentos anos, Aristóteles estabeleceu uma diferenciação entre dois tipos básicos de justiça, que ele denominou de justiça aritmétrica e justiça geométrica. Cerca de mil e quinhentos anos depois, Tomás de Aquino introduziu dois termos diferentes para designar tais modalidades de justiça e que hoje ainda são amplamente utilizados, seja na jurisprudência europeia continental, seja no ambiente anglo-saxão: justiça comutativa e justiça distributiva. De acordo com a concepção ainda amplamente dominante na Alemanha, tais formas de justiça se distinguem pelo fato de que as exigências da justiça comutativa devem ser realizadas sem que se leve em conta a pessoa concretamente considerada, ao passo que os predicados da justiça distributiva exigem sejam consideradas as condições de cada pessoa.

Diante desse pano de fundo eu devo, antes de mais nada, endereçar um elogio à justiça comutativa e com isso também ao "Mercado", na condição de meio para impedir discriminações na esfera do Direito Privado, ainda que isso venha a soar como contrário ao espírito contemporâneo (Zeitgeist). Com efeito, pelo fato de as valorações com base na justiça comutativa ocorrerem sem consideração da pessoa, sequer há margem para que ocorram discriminações propriamente ditas; estas costumam ser voltadas ex praemissione às pessoas, ao passo que na perspectiva do "Mercado" o que importa é a prestação como tal, que independe da cor da pele, da orientação religiosa ou da nacionalidade do prestador. A estrutura e o princípio fundamental do "Mercado" correspondem, portanto, a uma moral de cunho "universal", no sentido de uma moral igual para todos os seres humanos, sendo, de tal sorte, extremamente "humanos", o que há de ser enaltecido em homenagem às virtudes do "Mercado". Assim, por exemplo, um locador que rejeita um locatário em virtude de sua cor da pele, religião ou motivo similar, age de modo evidentemente contrário aos princípios elementares da economia de mercado.

Todavia, é do conhecimento geral que esse tipo de conduta sempre volta a ocorrer, pois os seres humanos nem sempre agem como autênticos homo oeconomicus, mas deixam-se conduzir frequentemente por motivações irracionais ou não objetivas. Aqui abrem-se espaços para intervenções corretivas por parte do Direito, pelo menos quando se cuida de casos crassos. A regulação, em tais casos, ocorre de modo consequente mediante consideração da pessoa, designadamente por meio de proibições dirigidas aos atores privados, no sentido de tratar de modo diferente as pessoas em virtude da cor de sua pele, religião, nacionalidade, etc. Nessa perspectiva, as proibições de discriminação assumem a função de portas de entrada para a justiça distributiva na esfera do Direito Privado, aspecto que por mim até o presente momento não foi suficientemente considerado e que hoje tenho a oportunidade de pronunciar pela primeira vez com toda a clareza. 
III.

Seria possível objetar que proibições de discriminação não têm caráter de Direito Privado, mas sim, de Direito Público, notadamente pelo fato de assumirem a condição de direito cogente e pelo fato de que não fosse assim não alcançariam a necessária eficiência. Tal objeção, contudo, não resiste a um exame mais aprofundado.

As duas principais explicações para a distinção entre Direito Público e Direito Privado são atualmente a teoria da sujeição e a teoria do sujeito. A primeira se baseia na circunstância de se uma das partes afetadas encontra-se numa esfera hierárquica inferior ou de algum modo está juridicamente subordinada à outra. Isso com certeza não se verifica no caso de proibições de discriminação na esfera do Direito Privado, como se dá nas relações entre empregador e empregado, locador e locatário, vendedor e comprador, fornecedor e tomador do crédito, etc. De acordo com a teoria dos sujeitos o que importa é se no polo da relação jurídica encontra-se (ou como tal atua) pelo menos uma pessoa de Direito Público. Para além do risco de se enveredar por um raciocínio circular, também nessa hipótese as proibições de discriminação eventualmente incidentes têm caráter indubitavelmente jurídico-privado, já que ambas as partes agem na condição de sujeitos de Direito Privado.

Pessoalmente prefiro adotar um critério de distinção algo diverso, que me parece mais consequente e correto. Eu tenho como preferível examinar se nos dois polos da relação jurídica é possível identificar um titular de direitos fundamentais, ou não. Apenas no primeiro caso cuida-se, de acordo com meu entendimento, de uma relação de Direito Privado. Não tenho condições de desenvolver aqui esse aspecto, mas quero, no entanto, ao ensejo dessa oportunidade para mim tão honrosa, colocar pela primeira vez em discussão. Quanto ao resultado, é preciso enfatizar, também nada restaria alterado em se seguindo esse modo de entender, pois nos casos em que o problema se coloca sempre atuam atores privados em ambos os polos da relação, de tal sorte que também nessa perspectiva se trata de Direito Privado.

Com isso o resultado, que já havia anunciado, resta claramente ratificado: proibições de discriminação representam a mais importante porta de ingresso da justiça distributiva, isto é, de uma justiça voltada à consideração da Pessoa, no Direito Privado, de tal sorte que tais proibições de discriminação com isso assumem caráter jurídico-privado.

IV.

Na sequência surge naturalmente a indagação acerca das razões pelas quais o Direito Privado contempla proibições de discriminação. A resposta não me parece completamente clara: pelo fato de que uma parte especialmente significativa das discriminações se manifesta no plano das relações entre seres humanos, portanto, no campo do Direito Privado. Para um alemão de 
minha geração isso não é uma convicção de natureza abstrata, mas sim, História vivenciada. Fui profundamente afetado pelo fato de no ano de 1943, quando contava com seis anos de idade, vi dois seres humanos trajando longos mantos pretos e que portavam nas suas costas uma estrela amarela, quando minha mãe, como reação à minha irritada pergunta sobre "o porquê", com manifesto constrangimento apenas soube responder que se tratava de "Judeus". Precisamente como criança se tem uma especial sensibilidade para reconhecer que algo de substancialmente errado está ocorrendo. Hoje podemos formular com clareza: a discriminação é aqui censurável pelo fato de implicar simultaneamente uma violação da dignidade humana.

Isso, no entanto, nem sempre é o caso, especialmente (embora não sempre) quando se está em face de uma discriminação do tipo mediato ou indireto. Nesse caso o que ocorre é que um determinado grupo de pessoas, em determinadas circunstâncias e em certos ambientes - por exemplo, no campo das diversas profissões - encontra-se fortemente subrepresentado. Assim, por exemplo, verifica-se ampla discussão no âmbito da União Europeia e na Alemanha sobre o fato de que as mulheres são mais raramente representadas nos círculos dirigentes e conselhos das empresas. Cogita-se, nesse contexto, em corrigir tal estado de coisas mediante recurso a sistemas de cotas mínimas implantadas por meio da legislação, ou seja, na introdução de uma "discriminação positiva" em favor das mulheres, uma espécie de ação afirmativa. De acordo com o meu ponto de vista tal alternativa está essencialmente aberta ao legislador, muito embora nada tenha a ver com a proteção da dignidade humana das mulheres. Afirmar o contrário é que implicaria uma desconsideração da dignidade humana daquelas mulheres que percebem as coisas de modo diverso e que tem outra representação de suas funções primárias, almejando dedicar-se em primeiro lugar à educação dos filhos e cuidados domésticos. Aqui está em causa se a sociedade e a Política desejam favorecer um novo papel da mulher no plano da vida profissional.

De acordo com o exposto, proibições de discriminação podem cumprir funções altamente diferenciadas e não devem de modo algum reivindicar sem exceção o elevado pathos de servirem à proteção da dignidade humana.

$\mathrm{V}$.

A partir desse ponto de partida é possível agora responder com facilidade a última pergunta central, qual seja: as proibições de discriminação no âmbito do Direito Privado geram efeitos de modo direto ou apenas indireto (mediato), mormente quando sediadas em camadas hierarquicamente superiores da ordem jurídica, como é o caso do Direito Europeu ou do Direito Constitucional?

A resposta há, no meu entender, de ser diferenciada. A eficácia imediata assume seu papel quando uma proibição de discriminação serve à proteção da dignidade humana, pois esta, em virtude de sua supremacia absoluta, opera sempre de modo direto. Isso significa acima de tudo que tal proibição 
de discriminação há de ser sempre assegurada pelo Poder Judiciário. Nos casos de proibições de discriminação que tenham por objeto a consecução de fins de natureza profissional, social ou política, a prerrogativa da formatação encontra-se nas mãos do Poder Legislativo. Aqui o Poder Judiciário não poderá acessar o instrumental da eficácia direta das proibições de discriminação na esfera das relações privadas.

VI.

Minhas senhoras e meus senhores: eu lhes sou grato pela paciência e pela concentração com as quais acompanharam meus pensamentos.

Elevada Faculdade: eu mais uma vez agradeço pela grande honra que me concederam e pela extraordinária alegria com a qual me brindaram. 